\title{
Potato Starch Nanocrystal Preparation via Supercritical Carbon Dioxide Pretreatment Combined With Enzymatic Hydrolysis
}

\author{
Hervé M. Nlandu, Nasima Chorfa, Khaled Bekacemi, ${ }^{\dagger}$ and Safia Hamoudi * \\ In this work, starch nanocrystals were successfully produced from \\ downgraded potatoes using enzymatic hydrolysis combined with a \\ supercritical carbon dioxide pretreatment to improve the accessibility of \\ the enzyme to the starches. Enzymatic hydrolysis was carried out using \\ the pullulanase enzyme at a temperature of $60^{\circ} \mathrm{C}$ and a pH of 4 . Following \\ hydrolysis, the starch nanoparticles were recovered via precipitation and \\ recrystallization. Comparative characterization of the native, supercritical \\ carbon dioxide-pretreated, and hydrolyzed-recrystallized starch materials \\ was conducted via transmission electron microscopy, scanning electron \\ microscopy, Fourier transform infrared spectroscopy, and X-ray \\ diffraction. The scanning electron microscopy images revealed alterations, \\ e.g., layered strips, on the surface of the potato starch granules after the \\ supercritical carbon dioxide pretreatment. The transmission electron \\ microscopy images revealed that spherical nanostructures from $80 \mathrm{~nm}$ to \\ $150 \mathrm{~nm}$ were successfully produced. The Fourier transform infrared \\ spectroscopy spectra displayed several absorption bands corresponding \\ to the molecular structure of starches. The X-ray diffractograms exhibited \\ a typical B-type scattering pattern for all the samples. In addition, it was \\ found that the crystallinity of the potato starch nanoparticles was \\ considerably increased compared with native starch.
}

Keywords: Potato starch nanoparticles; Supercritical $\mathrm{CO}_{2}$; Pullulanase; Hydrolysis; Nanoprecipitation

Contact information: Department of Soil Sciences and Agrifood Engineering, Centre for Green Chemistry and Catalysis, Université Laval, Québec G1V 0 A6 Canada; † The late professor

Khaled Belkacemi passed away in the attack perpetrated at Québec City on January 29th, 2017;

* Corresponding author: safia.hamoudi@fsaa.ulaval.ca

\section{INTRODUCTION}

Starch is the second most abundant carbohydrate polymer after cellulose in the biosphere. Starch is used in numerous industrial applications due to its low cost, availability, biodegradability, biocompatibility, and derivability (Tan et al. 2009). It is a major source of carbohydrates in animal and human food and is also used in non-food industrial sectors, e.g., paper, pharmaceutics, cosmetics, textiles, etc. (Boursier 2005). Newer and more advanced applications utilizing starch have been continuously explored in the last decade (Xiao 2013; Zhang et al. 2014). For instance, starch was used as a precursor material in the synthesis of starch-based nanoparticles for various biomedical and industrial applications, e.g., drug delivery carriers (Rodrigues and Emeje 2012) and biodegradable edible films (Gonzalez and Igarzabal 2015).

Basically, starch consists of two molecules: the linear and helical $\alpha$-Dglucopyranose, consisting of glucose units linked by $\alpha-(1-4)$ bonds (amylose: $20 \%$ to $30 \%$ in typical potatoes) with a molecular weight of $10^{6} \mathrm{Da}$; and the branched amylopectin $(70 \%$ 
to $80 \%$ ) consisting of glucose units with $\alpha-(1-6)$ bonds, with a molecular weight of approximately $10^{10}$ Da (Odeku 2013). Potato starch occurs naturally in the form of insoluble, semi-crystalline granules. Each granule has a layered organization with alternating amorphous and semi-crystalline growth rings with similar 120 to $400 \mathrm{~nm}$ thicknesses (Gallant et al. 1997).

Starch nanoparticles derive from the disruption of the semi-crystalline structure of starch granules. Such particles are valuable in food packaging technology because they can enhance the mechanical and water vapor resistance of a polymer. In medicine, starch nanoparticles are appropriate as carriers for the drug delivery of immobilized bioactive or therapeutic agents. Starch nanoparticles with different physicochemical and mechanical properties were obtained using various preparation methods (Aldao et al. 2018)

Several researchers reported three widely used methods for the preparation of starch nanoparticles, namely acid or enzymatic hydrolysis, regeneration, and mechanical methods (LeCorre et al. 2010). The resulting materials from such methods may be nanocrystals, nanoparticles, or nano-colloids. Generally, nanocrystals are produced through enzymatic and acid hydrolysis, nanoparticles are obtained via regeneration and precipitation processes, while nano-colloids, which are solid nanoparticles dispersed in a liquid medium, are produced by mechanical treatments, e.g., high-pressure homogenization and reactive extrusion (Kumari et al. 2020). To increase the yield of starch nanoparticle production, acid hydrolysis combined with ultrasonication (Kim et al. 2013; Rodríguez-Pineda et al. 2018), and nanoprecipitation (Wu et al. 2019) were reported. Nanoprecipitation is also a promising method, as it does not require specialized equipment or complex operating conditions. The associated costs are reasonably low, and the risk of sample contamination is often considerably reduced. As for the mechanical treatment processes, the primary drawback is related to their high energy consumption. The enzymatic hydrolysis of starch has an advantage over acid hydrolysis of being faster with higher yields (Aldao et al. 2018). In addition, acid hydrolytic treatment processes pose a problem in the form of the recovery of chemicals.

Recently, the use of green technologies, e.g., the combination of pretreatments using supercritical $\mathrm{CO}_{2}\left(\mathrm{SC}-\mathrm{CO}_{2}\right)$ with the enzymatic hydrolysis of different biomass materials, has received great interest (Silveira et al. 2015; Baruah et al. 2018). The use of active enzymes to modify carbohydrates is an extremely selective and versatile biotechnological tool. Moreover, supercritical $\mathrm{CO}_{2}$ ensures a mass transfer similar to that of gases and has a solvating power identical to liquids. Such characteristics make $\mathrm{SC}-\mathrm{CO}_{2}$ more easily penetrate the micropores of the biomass. The sudden release of this fluid causes the disaggregation of the previously impregnated biomass, which becomes more accessible to enzymatic hydrolysis. In addition, enzymatic processes, which are carried out under mild conditions, are specific, regio-selective, and environmentally friendly, which is not the case for chemical processes. They can therefore be used effectively after a pretreatment step to ensure the desired modification of the targeted biomass. The supercritical $\mathrm{CO}_{2}$ pretreatment process is also convenient, owing to its low critical coordinates (a temperature of $31{ }^{\circ} \mathrm{C}$ and a pressure of $7.38 \mathrm{MPa}$ ) when compared to supercritical water for instance. Furthermore, $\mathrm{SC}-\mathrm{CO}_{2}$ exhibits interesting advantages, including non-inflammability, nontoxicity, availability at relatively low costs and high purity, recyclability, and volatility at atmospheric pressure, thus allowing an easy separation from the treated compounds without leaving toxic residues in the extracts (Chemat et al. 2017).

The aim of the present investigation was the synthesis of nanocrystals from potato starch granules via enzymatic hydrolysis combined with supercritical carbon dioxide 
pretreatment and nanoprecipitation. To the best of the knowledge of the authors, no study has been performed on the use of this combination to produce potato starch nanocrystals.

\section{EXPERIMENTAL}

\section{Materials}

The starch used in this study was extracted from potatoes produced by La Ferme Valupierre (Quebec, Canada) and marketed under the brand name Gabrielle. Sodium azide $\left(\mathrm{NaN}_{3}\right)$, sodium nitrate $\left(\mathrm{NaNO}_{3}\right)$, a citric acid/sodium hydroxide/hydrogen chloride buffer solution at a $\mathrm{pH}$ of 4 , as well as pulullanase enzyme were purchased from Sigma-Aldrich and used without further purification. An industrial grade gas cylinder of $\mathrm{CO}_{2}$ was purchased from Praxair Canada Inc. (Mississauga, Ontario, Canada).

\section{Methods}

All the tests, analyses, and characterizations were performed in triplicate. In addition, the different analyses were repeated twice for the same sample and each value reported herein is the average of the duplicate measurements.

\section{Potato starch extraction}

Potato starch was isolated according to the methods in Singh et al. (2008) with slight modification. Peeled potato was ground using a blender (707SB, Waring Commercial, Torrington, CT) with distilled water and filtered stepwise through cheese cloth. The residues and the top purplish layer were discarded, and the remaining precipitate starch slurry was washed with distilled water, centrifuged at $10000 \mathrm{r} / \mathrm{min}$ for $5 \mathrm{~min}$, and then freeze-dried.

\section{Supercritical $\mathrm{CO}_{2}$ pretreatment of the potato starch}

The supercritical $\mathrm{CO}_{2}$ pretreatment was conducted in a $1 \mathrm{~L}$ stainless-steel highpressure autoclave mounted on a pressure pump capable of operating up to 6000 PSI, connected to a $\mathrm{CO}_{2}$ cylinder and a thermostatic bath, which made it possible to achieve and maintain the $\mathrm{CO}_{2}$ under supercritical conditions (a pressure greater than 1073 PSI and a temperature greater than $31{ }^{\circ} \mathrm{C}$ ). In a typical run, according to the previous work of the authors, with slight modification (Nlandu et al. 2019), the reactor was loaded with $20 \mathrm{~g}$ of native potato starch. Then liquid $\mathrm{CO}_{2}$ was aspirated from a cylinder equipped with a dip tube and pressurized by a motorized pump to 2000 PSI. The temperature of the thermostatic bath was adjusted to heat the double wall of the reactor to a temperature of $70{ }^{\circ} \mathrm{C}$. Then, the starch sample was exposed to supercritical $\mathrm{CO}_{2}$ for $1 \mathrm{~h}$. At the end of operation, a quick pressure release was performed by opening a valve attached to the reactor, thus bringing the pressure levels back to atmospheric conditions. The obtained pretreated starch sample was dried at room temperature for $24 \mathrm{~h}$ before further treatments and analyzes.

\section{Enzymatic hydrolysis}

A preliminary investigation on the enzymatic hydrolysis of the native and supercritical $\mathrm{CO}_{2}$-pretreated potato starch was conducted under different operating conditions to optimize the hydrolysis reaction. The obtained results showed that the process was optimized at a temperature of $60{ }^{\circ} \mathrm{C}$ and in a buffer solution with a $\mathrm{pH}$ of 4 . 
Consequently, all the enzymatic hydrolysis processes performed in the present investigation were conducted under these optimized conditions. In a typical run, the native and supercritical $\mathrm{CO}_{2}$-pretreated starch samples were mixed in a buffer solution with a $\mathrm{pH}$ of $4.0(5 \%(\mathrm{~W} / \mathrm{V}))$ in a $250 \mathrm{~mL}$ Erlenmeyer. For better dispersion of the starch, the suspension was sonicated at an amplitude of $22 \%$ for 20 min using a high-intensity ultrasonic processor (750 W Model, $20 \mathrm{kHz}$ from Branson Ultrasonics Corporation; Danbury, CT, USA). Boiling water was then added to the dispersion and vigorously stirred for $20 \mathrm{~min}$, until complete starch gelatinization was achieved. After cooling the gelatinized starch to a temperature of $60{ }^{\circ} \mathrm{C}$, pullulanase (135 npun/g of dry starch) was added. After $7 \mathrm{~h}$ of enzymatic hydrolysis, the reaction was stopped, and the suspension was put into a boiling water bath for 15 min to deactivate the enzyme. The mixture was then centrifuged at $10000 \mathrm{rpm}$ for $5 \mathrm{~min}$ to remove the precipitate. Ethanol, in a 1 to $10 \mathrm{ratio}$, was added to the gelatinized supernatant solution for $24 \mathrm{~h}$ at a temperature of $4{ }^{\circ} \mathrm{C}$. Afterwards, the precipitation could be achieved by causing supersaturation, followed by nuclei and particle growth, causing the colloidal starch particles to subsequently form. The suspension was centrifuged at $10000 \mathrm{rpm}$ and a temperature of $5{ }^{\circ} \mathrm{C}$ for $5 \mathrm{~min}$ and the obtained precipitate was freeze-dried leading to debranched starch particles in powder form. These particles were put in water $(5 \%)$, reheated to a temperature of $120{ }^{\circ} \mathrm{C}$ for $30 \mathrm{~min}$, stored at a temperature of $4{ }^{\circ} \mathrm{C}$ for $24 \mathrm{~h}$, then oven-dried at a temperature of $30^{\circ} \mathrm{C}$ for $24 \mathrm{~h}$, and finally milled and passed through a 140-mesh sieve to obtain the potato starch nanocrystals.

\section{Monitoring of the enzymatic hydrolysis reaction kinetics}

During the enzymatic hydrolysis reaction, $1 \mathrm{~mL}$ aliquots of the suspension were taken after 1, 2, 3, 4, 5, 6, and $7 \mathrm{~h}$ to determine the amylose content, which was evaluated according to the methods outlined in Morrison and Laignelet (1983). Hence, $1 \mathrm{~mL}$ of dimethyl sulphoxide (DMSO) was added to $1 \mathrm{~mL}$ of the $5 \%$ starch suspension in glass test tubes and incubated in a water bath at a temperature of $85{ }^{\circ} \mathrm{C}$ for $15 \mathrm{~min}$. The suspension was cooled down to room temperature, vortexed, and then diluted to $25 \mathrm{~mL}$ with distilled water. Then, $1 \mathrm{~mL}$ of the sample was diluted again with distilled water (up to $50 \mathrm{~mL}$ ) in a volumetric flask, and an iodine solution $(5 \mathrm{~mL})$ was added to the sample solution. The iodine solution was prepared by mixing iodine and potassium iodide in distilled water to get a concentration of iodine ( $\left.\mathrm{I}_{2}\right)$ and potassium iodide $(\mathrm{KI})$ of $0.0025 \mathrm{M}$ and $0.0065 \mathrm{M}$, respectively. The solution was then analyzed using a spectrophotometer (Spectronic Genesys 20, Thermo Fisher Scientific, Waltham, MA, USA) at a wavelength of $635 \mathrm{~nm}$.

\section{Size-exclusion chromatography}

The molecular weight distribution of the native and treated starches was determined via size exclusion chromatography coupled with a refractive index detection. Starch samples $(10 \mathrm{mg})$ were suspended in $10 \mathrm{~mL}$ of buffer $\left(3.1 \mathrm{mM} \mathrm{NaN}_{3}\right.$ and $0.1 \mathrm{M} \mathrm{NaNO}_{3}$, at a pH of 6) at a temperature of $60^{\circ} \mathrm{C}$ for $4 \mathrm{~h}$. The suspensions were filtered through a $5 \mu \mathrm{m}$ filter and $50 \mu \mathrm{L}$ of the filtrate was injected into a an HPLC device (Agilent series 1100) equipped with a Waters 2414 refractive-index detector, and two TSK gel columns (G6000PWxl and G4000PWxl) were used in tandem at a temperature of $60{ }^{\circ} \mathrm{C}$. The TSK gel G6000PWxl column is ideally suited for the analysis of water-soluble linear polymers with molecular weights up to $8 \times 106 \mathrm{Da}$. The TSK gel G4000PWxl is ideally suited for

the analysis of water-soluble linear polymers with molecular weights up to $3 \times 10^{5} \mathrm{Da}$. The buffer was used as a mobile phase at a low rate of $0.4 \mathrm{~mL} / \mathrm{min}$. The pullulan standards: P$1600\left(M_{\mathrm{w}}=166.00 \times 10^{4} \mathrm{~g} / \mathrm{mol}\right), \mathrm{P}-400\left(M_{\mathrm{w}}=38.00 \times 10^{4} \mathrm{~g} / \mathrm{mol}\right), \mathrm{P}-200\left(M_{\mathrm{w}}=18.60 \times\right.$ 
$\left.10^{4} \mathrm{~g} / \mathrm{mol}\right), \mathrm{P}-100\left(M_{\mathrm{w}}=10.00 \times 10^{4} \mathrm{~g} / \mathrm{mol}\right), \mathrm{P}-50\left(M_{\mathrm{w}}=4.80 \times 10^{4} \mathrm{~g} / \mathrm{mol}\right), \mathrm{P}-20\left(M_{\mathrm{w}}=\right.$ $\left.2.37 \times 10^{4} \mathrm{~g} / \mathrm{mol}\right), \mathrm{P}-10\left(M_{\mathrm{w}}=1.22 \times 10^{4} \mathrm{~g} / \mathrm{mol}\right)$, and P-5 $\left(M_{\mathrm{w}}=0.58 \times 10^{4} \mathrm{~g} / \mathrm{mol}\right)$, were used to determine the molecular weight of the samples. The data obtained from the RI detector was analyzed using OpenLAB CDS ChemStation software (Rev C.01.07, Agilent Technologies, Santa Clara, CA, USA).

\section{Characterization}

The native and different pretreated starch samples were mixed and ground with $\mathrm{KBr}$ in a weight ratio of 1 to 100 to prepare the pellets. The infrared spectra were obtained using a Varian 1000 FTIR spectrometer (Scimitar series, Foster City, CA, USA) and recorded at wavenumbers between 4000 and $400 \mathrm{~cm}^{-1}$.

The surface morphology of the native and different pretreated starches was examined using a scanning electron microscope (JEOL 840-A, Tokyo, Japan) operated at an accelerating voltage of 10 to $20 \mathrm{kV}$. Before analysis, the samples were prepared via sputter coating with platinum to obtain conductive surfaces.

The microstructure and sizing of the potato starch samples were investigated using a transmission electron microscope (JEOL JEM-1230) at an accelerating voltage of $80 \mathrm{kV}$. Before analysis, each representative sample was suspended in ethanol and sonicated for 5 min. Then, a drop of the suspension was placed on a carbon microgrid and dried at a temperature of $60{ }^{\circ} \mathrm{C}$ for $20 \mathrm{~min}$.

The X-ray powder diffraction data of the native and different pretreated starch samples were collected on a Rigaku D-Max-Ultima III diffractometer (The Woodlands, TX, USA) using nickel-filtered $\mathrm{Cu}-\mathrm{K} \alpha$ with a wavelength of $1.5406 \AA$ at a voltage of 40 $\mathrm{kV}$ and a current of $44 \mathrm{~mA}$. Powder diffraction patterns were obtained between $5^{\circ}$ and $55^{\circ}$ with a scan speed of 2 degree/min. The degree of crystallinity of the starch samples was quantitatively estimated as the ratio of the area of the crystalline reflections to the overall diffraction area as previously reported by Nara and Komiya (1983) and Jiang et al. (2016), and shown in Eq. 1,

$$
\text { Relative crystallinity }(\%)=\frac{\text { Area under the peaks }}{\text { Total curve area }} \times 100
$$

\section{RESULTS AND DISCUSSION}

\section{Production of the Starch Nanocrystals}

Pullulanase is well known as a debranching enzyme in the hydrolysis of native starch. This enzyme can produce starch with high amylose content (Wong et al. 2007). In this work, a starch pretreatment process utilizing supercritical $\mathrm{CO}_{2}$ was conducted to improve the accessibility of the enzyme to starch. The effect of this pretreatment on the production of high amylose starch is shown in Fig. 1. The addition of this pretreatment resulted in a runnier solution after letting the reaction run for $7 \mathrm{~h}$. The starch suspension was initially very viscous with the initial amylose concentration at $76 \mathrm{mg} / \mathrm{L}$ for all samples, corresponding to an amylose content of 20\%. As depicted in Fig. 1, the hydrolysis proceeded at a rapid rate during the first hour of the reaction, leading to a considerable increase in the amylose content, which indicated that the enzyme effectively broke down the starch by hydrolyzing the $\alpha-1,6$ bonds of amylopectin. As the reaction time increased, the rate of hydrolysis slowed down and the amylose concentration reached $312 \mathrm{mg} / \mathrm{L}$ (an 
amylose yield of $82 \%$ ) for the non-pretreated potato starch (A), which was in agreement with previously reported data by et al. (2012). For the supercritical $\mathrm{CO}_{2}$-pretreated starch (B), the amylose concentration reached $343 \mathrm{mg} / \mathrm{L}$ (an amylose yield of 90\%) after $7 \mathrm{~h}$ of hydrolysis. Clearly, the supercritical $\mathrm{CO}_{2}$ pretreatment improved the accessibility of starch to the enzyme, which translated into a higher amylose content in the hydrolyzed pretreated starch.

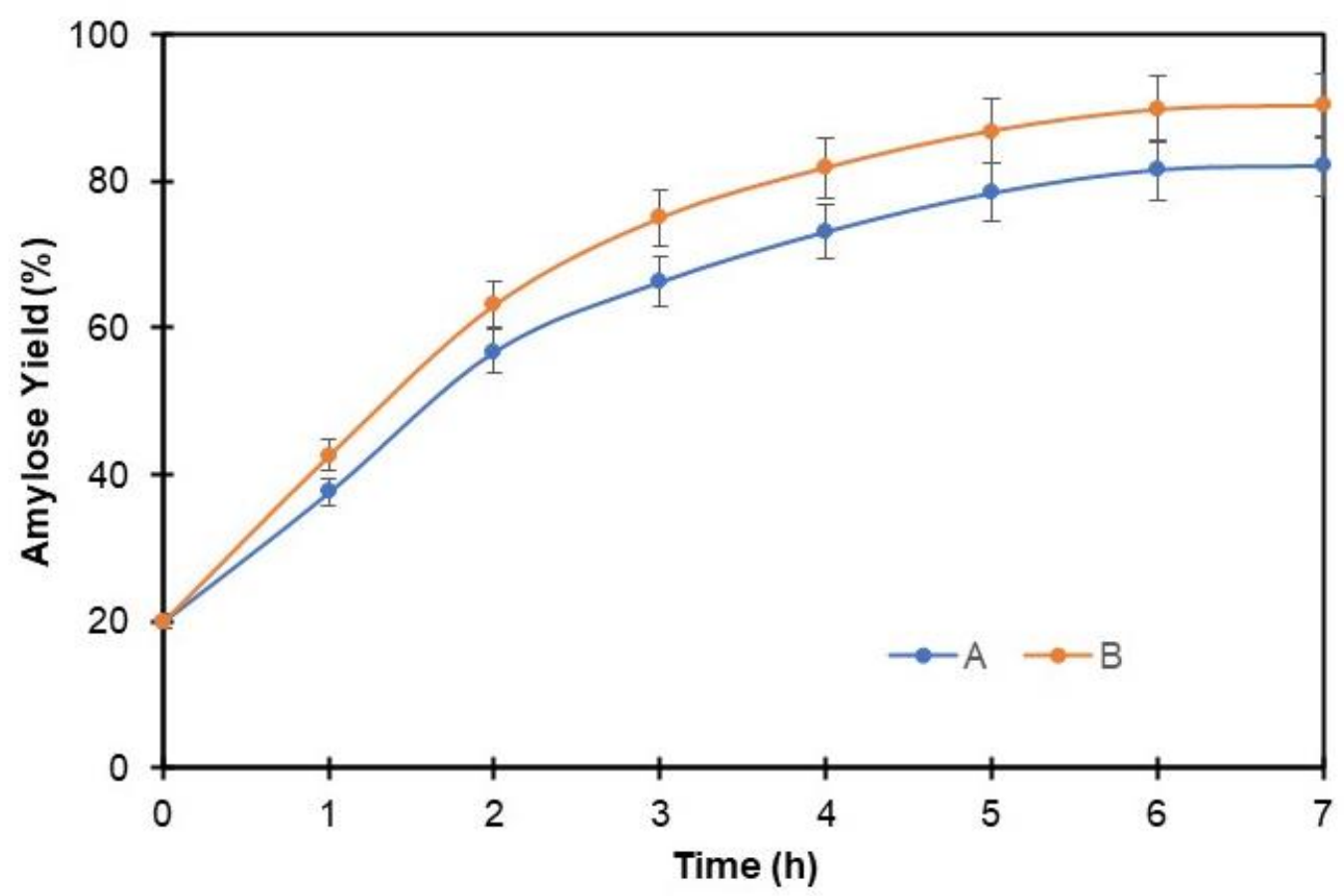

Fig. 1. Time profile of the amylose yield of hydrolyzed native potato starch (A) and $\mathrm{SC}-\mathrm{CO}_{2}-$ pretreated potato starch (B). Error bars denote standard deviation.

The molecular weight distributions of the branch chains of the potato starch nanocrystals are shown in Fig. 2. After hydrolysis with the addition of pullulanase, all the produced potato starch samples showed polymodal distributions with small, large, and extra-large molecular weight fractions of chain lengths at degrees of polymerization (DP) at approximately 13 to $18(\mathrm{~F} 1)$, DP 50 to $52(\mathrm{~F} 2)$, and DP 79 to $82(\mathrm{~F} 3)$, in accordance with previous literature (Fredriksson et al. 1997, 1998). The native and supercritical $\mathrm{CO}_{2}-$ pretreated starch samples led to starch nanocrystals containing large amounts of F3, i.e., approximately $98 \%$ and $68 \%$ fractions, respectively, indicating that they were primarily composed of branched chains of DP 80. In addition, the potato starch nanocrystals from the $\mathrm{SC}-\mathrm{CO}_{2}$-pretreated starch exhibited a large amount of the $\mathrm{F} 2$ fraction, i.e., $29 \%$ branched chains of DP 50, and a small amount of F1 fraction, i.e., 2\% minor branched chains of DP 17 and 13, whereas these fractions were not observed in the native starch. 


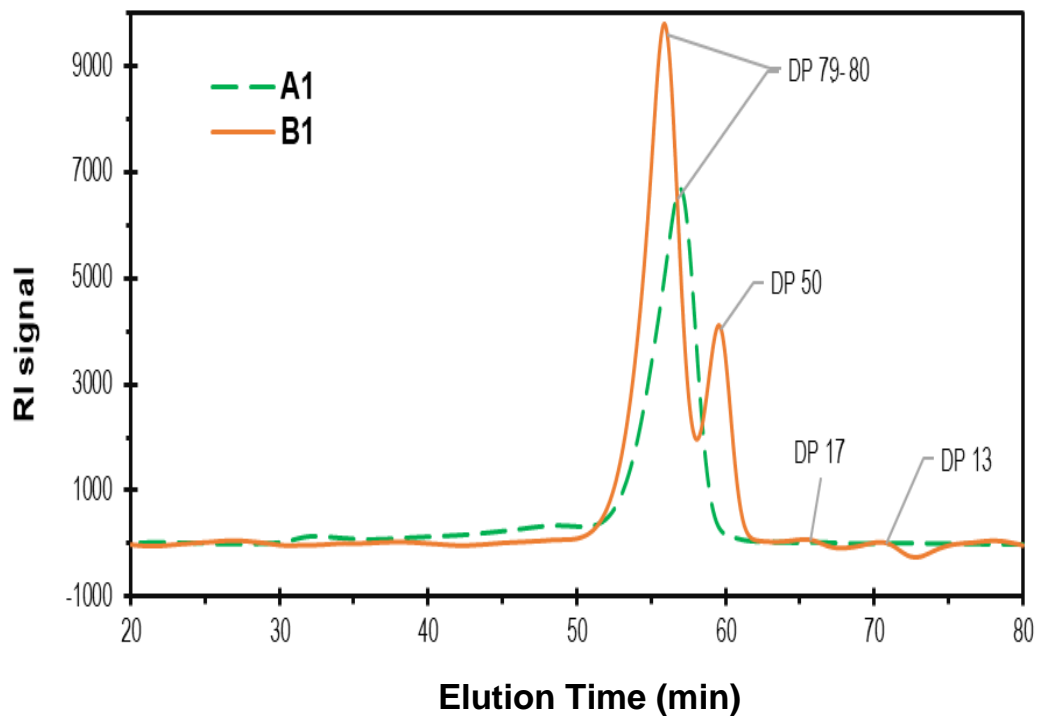

Fig. 2. Size exclusion chromatography of the potato starch nanocrystals from the native potato starch (A1) and the SC- $\mathrm{CO}_{2}$-pretreated potato starch (B1)

\section{Morphology of the Potato Starches}

For the sake of clarity, the terms commonly used, i.e., starch crystallite, starch nanocrystal, microcrystalline starch, and hydrolyzed starch, all refer to the crystalline part of starch obtained via hydrolysis but to a different extent (from the most to the least). These materials should be distinguished from starch nanoparticles, presented later, which can be amorphous (LeCorre et al. 2010). In the present investigation, potato starch nanocrystals were obtained via the enzymatic hydrolysis of $\mathrm{CO}_{2}$-pretreated starch using pullulanase enzymes, according to the methods outlined in Lu et al. (2019), with slight modification, and recrystallized according to Chang et al. (2020), with slight modification. Pullulanase enzyme selectively hydrolyzes the 1,6- $\alpha$-D-glycosidic bonds, leading to the formation of linear short chain molecules with a low molecular weight.

Scanning electron microscopy was used to compare the morphological changes in the potato starch after $\mathrm{SC}-\mathrm{CO}_{2}$. Figure 3 shows the $\mathrm{SEM}$ images of the native and $\mathrm{SC}_{-} \mathrm{CO}_{2}$ pretreated starches. The native potato starch granules were mostly quasi-spherical or polygonal with a smooth surface and flat edge (as shown in Fig. 3A), corroborating the structure described by Guo et al. (2020). Few layered strips on the surface of the $\mathrm{SC}_{-} \mathrm{CO}_{2}$ pretreated starch can be observed (Fig. 3B). The changes in the surface morphology could be used to explain the differences in the hydrolysis process of native and $\mathrm{SC}^{-\mathrm{CO}_{2}-}$ pretreated potato starch samples.

The TEM images of the potato starch nanocrystals are shown in Fig. 4. The images revealed that elongated spherical-like nanostructures with sizes ranging from $20 \mathrm{~nm}$ to 200 $\mathrm{nm}$ were produced. The nanocrystals stemming from the $\mathrm{SC}-\mathrm{CO}_{2}$-pretreated starch (B1) exhibited almost the same shape as the particles stemming from the native starch; however, their size was smaller, ranging from $20 \mathrm{~nm}$ to $150 \mathrm{~nm}$. These results were in agreement with previous observations reported by LeCorre et al. (2011) and Kim et al. (2012) for enzymatically hydrolyzed maize starch. These authors stated that the starch particles appeared to be in relation to the modification method, the crystalline structure of blocklets, and the amylose content of the original native starch. In addition, B-type starches, e.g., potato starch, gave rise to spherical-like particles. 

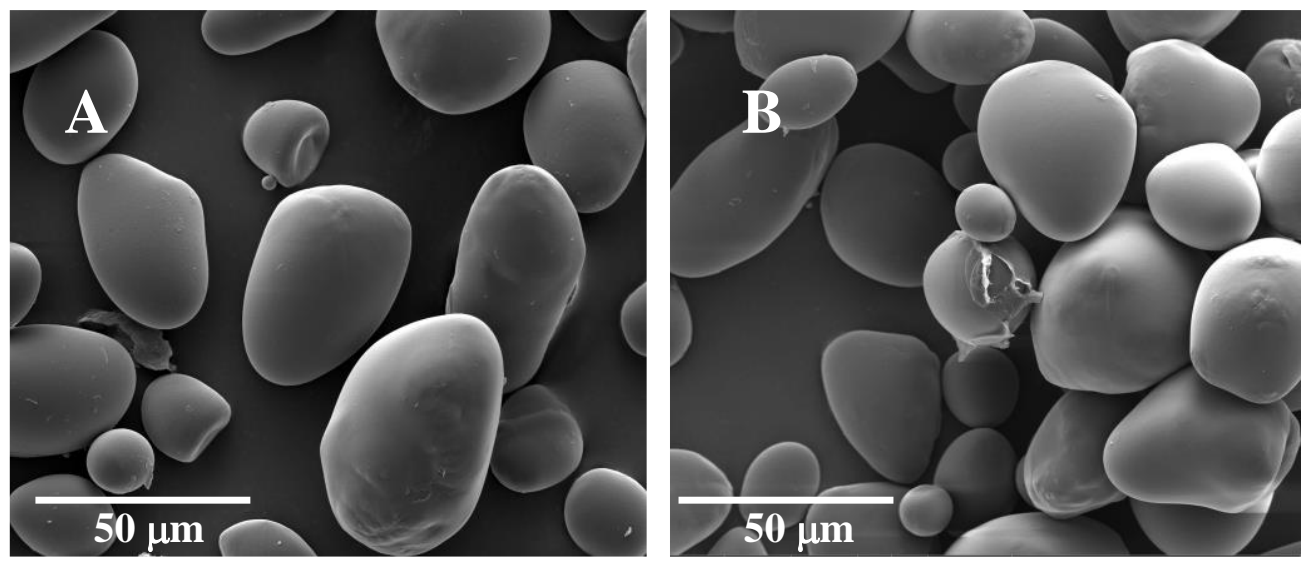

Fig. 3. SEM images of native potato starch (A) and $\mathrm{SC}-\mathrm{CO}_{2}$-pretreated potato starch (B).
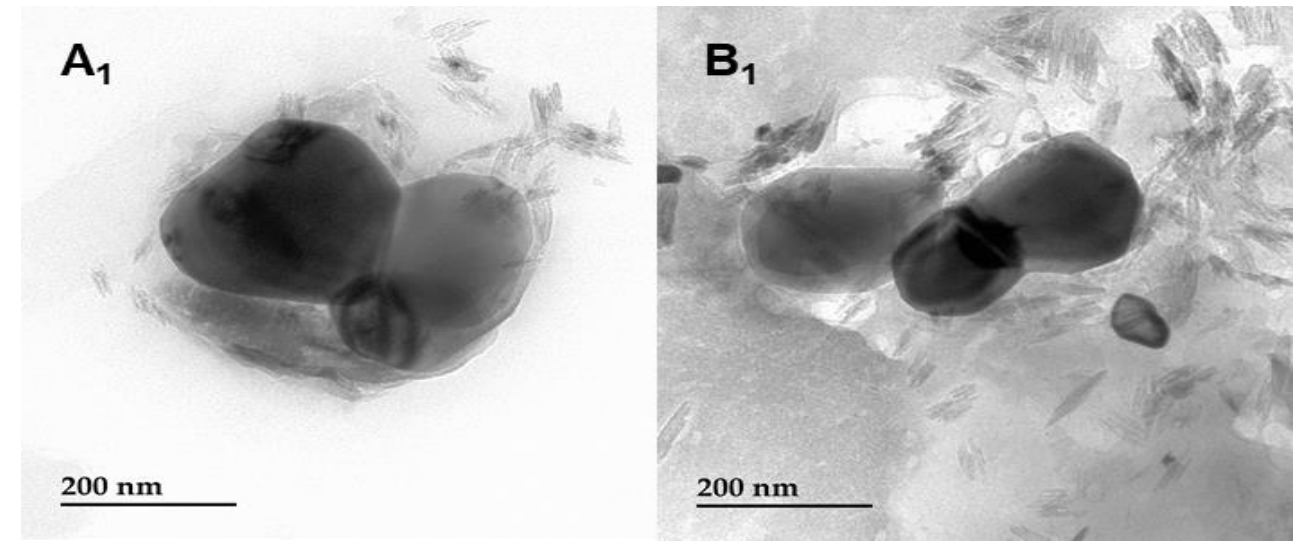

Fig. 4. TEM images of the potato starch nanocrystals from the native potato starch $(A 1)$ and from the SC-CO - -pretreated potato starch (B1).

Figure 5 shows the FTIR spectra of the native (A), SC-CO2-pretreated (B) starch samples (as shown in Fig. 5.1), and their corresponding nanocrystals (as shown in Fig. 5.2, A1 and B1). All the FTIR spectra exhibited several absorption bands that can be attributed to the molecular structure of starch. The bands at 1160 and $1018 \mathrm{~cm}^{-1}$ were attributed to $\mathrm{C}=\mathrm{O}$ and $\mathrm{C}-\mathrm{O}-\mathrm{C}$ stretching, respectively; the band at approximately $2950 \mathrm{~cm}^{-1}$ was ascribed to $\mathrm{C}-\mathrm{H}$ stretching, while the broad band at approximately $3400 \mathrm{~cm}^{-1}$ was assigned to the hydrogen bonded hydroxyl group stretching of the starch granules (Lammers et al. 2009). The absorbance band at approximately $1660 \mathrm{~cm}^{-1}$ was attributed to the bending vibration of the $\mathrm{O}-\mathrm{H}$ of bound water in the amorphous region, and the peaks at 1400 to $1450 \mathrm{~cm}^{-1}$ were attributed to $\mathrm{CH}_{2}$ twitching (Kizil et al. 2002). The peak at $995 \mathrm{~cm}^{-1}$ was related to the water-starch interaction, and its absorption intensity was produced by $\mathrm{C}-\mathrm{O}-$ $\mathrm{H}$ bending vibrations; this reflected the sensitivity of the sample to water, which is a characteristic of hydrophilicity of starch (Warren et al. 2016). Peaks observed between 766 and $995 \mathrm{~cm}^{-1}$ were due to the hydrogen bonding of an $\mathrm{OH}$ group, the skeletal mode vibration of the $\alpha-1,4$ glycosidic linkage, and C-C stretching (Reddy et al. 2017). 

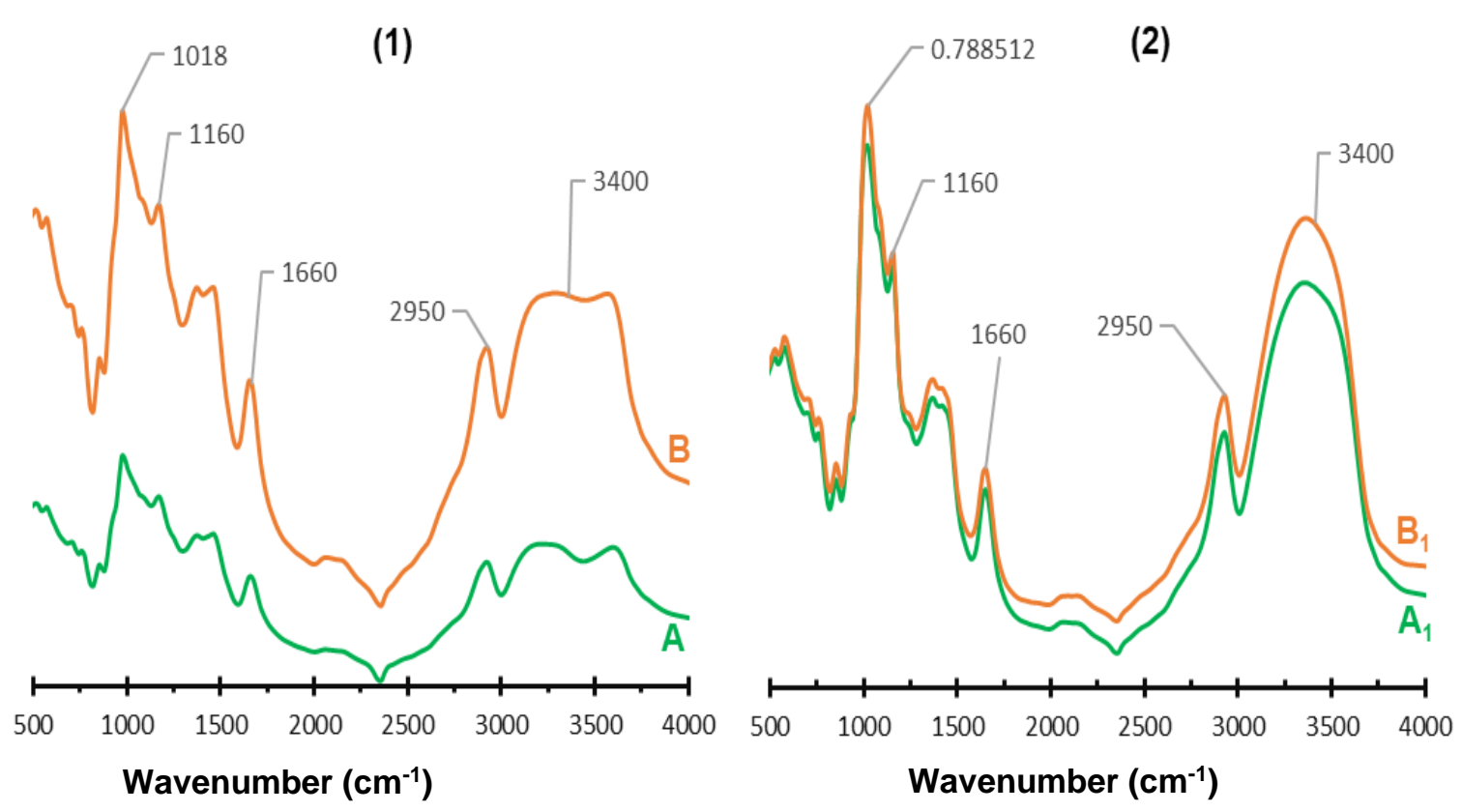

Fig. 5. FTIR spectra of (1) the native $(A)$ and $\mathrm{SC}-\mathrm{CO}_{2}$-pretreated $(\mathrm{B})$ potato starch samples, and (2) the corresponding nanocrystals (A1 and B1)

The X-ray diffractograms of the native (A), the $\mathrm{SC}-\mathrm{CO}_{2}$-pretreated (B) potato starch samples, and their corresponding nanocrystals (A1 and B1) are displayed in Fig. 6. Both exhibited the typical B-type scattering pattern with prominent diffraction peaks centered around $5.5^{\circ}, 17^{\circ}, 21^{\circ}$, and $23^{\circ}$. The relative crystallinity of the native samples (A) was $40.6 \%$, which was in agreement with the results reported by Cai and Shi (2010). The relative crystallinity of the $\mathrm{SC}-\mathrm{CO}_{2}$-pretreated potato starch sample was $44.4 \%$. After undergoing hydrolysis and directed crystallization, the obtained starch nanocrystals from the native (A1) and $\mathrm{SC}-\mathrm{CO}_{2}$-pretreated potato starch (B1) were $61.2 \%$ and $60.2 \%$, respectively.

No major change in the type of crystalline pattern was observed for the $\mathrm{SC}-\mathrm{CO}_{2}-$ pretreated starch nanoparticles when compared to the native starch, as the major peaks were similar. However, the $\mathrm{SC}-\mathrm{CO}_{2}$-pretreatment induced a slight increase in the relative crystallinity of the potato starch. This could be related to the $\mathrm{SC}-\mathrm{CO}_{2}$-pretreatment, which caused enough damage to the amorphous surface of potato starch, further exposing the crystalline regions and thus resulting in an increase in crystallinity (Nlandu et al. 2019). Compared to the relative crystallinity of the native (A) and $\mathrm{SC}-\mathrm{CO}_{2}$-pretreated starch (B) samples, the corresponding crystallinity of their nanocrystals (A1 and B1) was considerably increased. This was due to the fact that, after pullulanase enzyme debranching and directed crystallization, the amylopectin became the relatively short amylose, which is ideal for nanocrystal formation through self-assembly, i.e., the gelatinized starch is converted from an amorphous state to a more ordered or crystalline state (Miao et al. 2009; Shi and Gao 2011). 
(1)

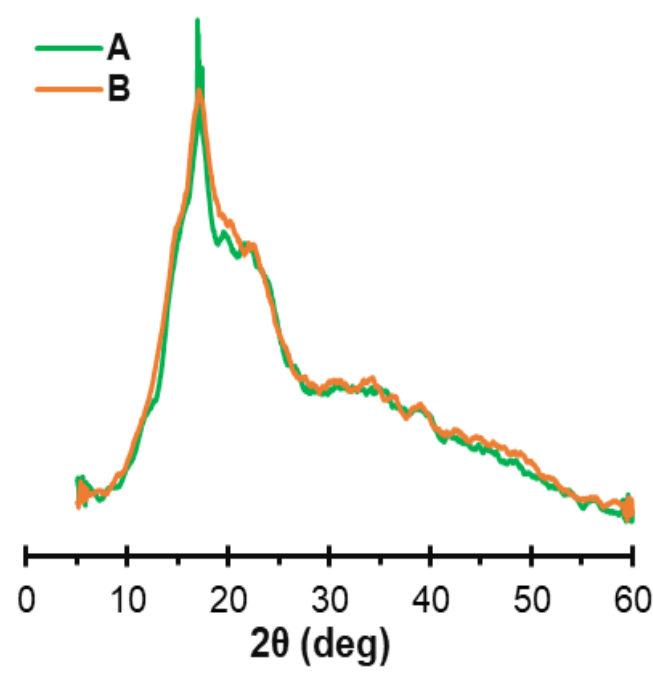

(2)

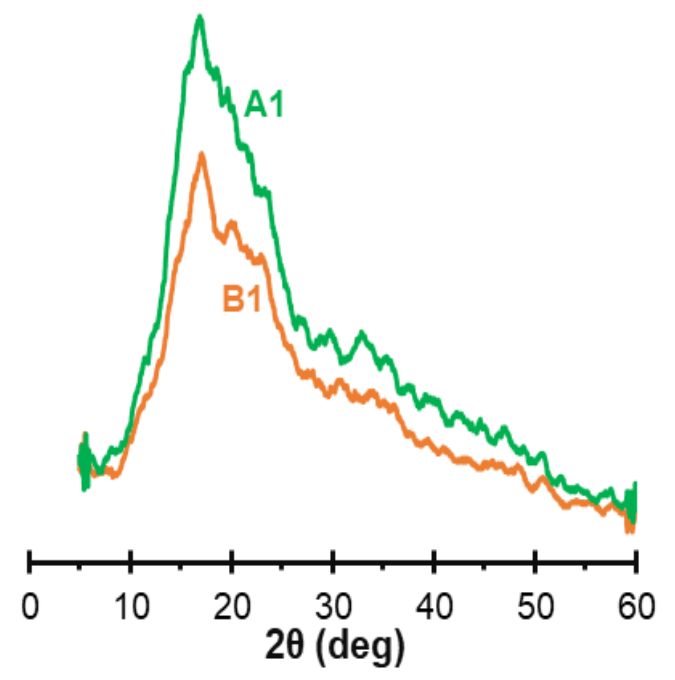

Fig. 6. XRD patterns of (1) the native $(A)$ and $\mathrm{SC}-\mathrm{CO}_{2}$-pretreated $(\mathrm{B})$ potato starch samples, and (2) the corresponding nanocrystals (A1 and B1)

\section{CONCLUSIONS}

1. In this study, potato starch nanocrystals were prepared via enzymatic hydrolysis combined with a supercritical (SC) carbon dioxide pretreatment and nanoprecipitation, followed by directed recrystallization.

2. Starch was extracted from potatoes and pretreated with supercritical $\mathrm{CO}_{2}$, and the effects of this pretreatment process on the properties of potato starch were investigated.

3. The scanning electron micrograph (SEM) results revealed few layered strips on the surface of the $\mathrm{SC}-\mathrm{CO}_{2}$-pretreated starch and the damages exposed the crystalline regions of the starch, which resulted in an increase in crystallinity from $40.6 \%$ to $44.4 \%$ after pretreatment. However, no change was observed in the quality of the chemical composition of the starch after the SC- $\mathrm{CO}_{2}$ pretreatment, as revealed by the Fourier transform infrared (FTIR) analysis. In addition, the $\mathrm{SC}-\mathrm{CO}_{2}$ pretreatment further improved the accessibility of the starches to the pullulanase enzyme. A difference of $10 \%$ in the amylose content was found after the hydrolysis of the pretreated starch samples compared to the native starch samples.

4. Enzymatic hydrolysis and nanoprecipitation yielded starch particles with nanometric dimensions and directed recrystallization led to nanocrystals with higher crystallinity. The potato nanocrystals obtained had a spherical shape with a diameter ranging from 20 to $150 \mathrm{~nm}$ and an increased crystallinity of approximately $60 \%$.

5. The nanocrystals obtained from the native starch were primarily composed of branched chains of DP 80 (98\%), while those obtained from the $\mathrm{SC}_{-} \mathrm{CO}_{2}$-pretreated starch were composed of branched chains of DP 50 (29\%) and DP 17-13 (2\%), in addition to branched chains of DP $80(68 \%)$. 


\section{ACKNOWLEDGMENTS}

The authors are grateful for the support of the Ministère de l'Agriculture, des Pêcheries et de l'Alimentation of Québec, Canada (Grant No. IA116564).

\section{REFERENCES CITED}

Aldao, D. C., Sarka, E., Ulbrich, P., and Mensikova, E. (2018). "Starch nanoparticles Two ways of their preparation," Czech Journal of Food Sciences 36(2), 133-138. DOI: $10.17221 / 371 / 2017-C J F S$

Baruah, J., Nath, B. K., Sharma, R., Kumar, S., Deka, R. C., Baruah, D. C., and Kalita, E. (2018). "Recent trends in the pretreatment of lignocellulosic biomass for value-added products," Frontiers in Energy Research 6, 1-19. DOI: 10.3389/fenrg.2018.00141

Boursier, B. (2005). "Amidons natifs et amidons modifiés alimentaires, Les techniques de l'ingénieur [Native and modified dietary starches, Engineer's techniques]," (https://www.techniques-ingenieur.fr/base-documentaire/procedes-chimie-bio-agroth2/additifs-et-adjuvants-alimentaires-42426210/amidons-natifs-et-amidons-modifiesalimentaires-f4690/), Accessed on March, 21 $1^{\text {st }}, 2021$.

Cai, L., and Shi, Y.-C. (2010). "Structure and digestibility of crystalline short-chain amylose from debranched waxy wheat, waxy maize, and waxy potato starches," Carbohydrate Polymers 79(4), 1117-1123. DOI: 10.1016/j.carbpol.2009.10.057

Chang, R., Tian, Y., Lu, H., Sun, C., and Jin, Z. (2020). "Effects of fractionation and heat-moisture treatment on structural changes and digestibility of debranched waxy maize starch," Food Hydrocolloids 101, 1-13. DOI: 10.1016/j.foodhyd.2019.105488.

Chemat, F., Rombaut, N., Meullemiestre, A., Turk, M., Perino, S., Fabiano-Tixier, A.-S., and Abert-Vian, M. (2017). "Review of green food processing techniques. preservation, transformation, and extraction," Innovative Food Science \& Emerging Technologies 41, 357-377. DOI: 10.1016/j.ifset.2017.04.016

Fredriksson, H., Andersson, R., Koch, K., and Åman, P. (1997). "Calibration of a sizeexclusion chromatography system using fractions with defined amylopectin unit chains," Journal of Chromatography A 768(2), 325-328. DOI: 10.1016/S00219673(97)00039-3

Fredriksson, H., Silverio, J., Andersson, R., Eliasson, A.-C., and Aman, P. (1998). "The influence of amylose and amylopectin characteristics on gelatinization and retrogradation properties of different starches," Carbohydrate Polymers 35(3-4), 119134. DOI: 10.1016/S0144-8617(97)00247-6

Gallant, D. J., Bouchet, B., and Baldwin, P. M. (1997). "Microscopy of starch: Evidence of a new level of granule organization," Carbohydrate Polymers 32(3-4), 177-191. DOI: $10.1016 / \mathrm{S} 0144-8617(97) 00008-8$

González, A., and Igarzabal, C. I. A. (2015). "Nanocrystal-reinforced soy protein films and their application as active packaging," Food Hydrocolloids 43, 777-784. DOI: 10.1016/j.foodhyd.2014.08.008

Guo, L., Li, J., Li, H., Zhu, Y., and Cui, B. (2020). "The structure property and adsorption capacity of new enzyme-treated potato and sweet potato starches," International Journal of Biological Macromolecules 144, 863-873. DOI: 10.1016/j.ijbiomac.2019.09.164 
Jiang, S., Liu, C., Wang, X., Xiong, L., and Sun, Q. (2016). "Physicochemical properties of starch nanocomposite films enhanced by self-assembled potato starch nanoparticles," LWT - Food Science and Technology 69, 251-257. DOI: 10.1016/j.lwt.2016.01.053

Kim, H.-Y., Lee, J. H., Kim, J.-Y., Lim, W.-J., and Lim, S.-T. (2012). "Characterization of nanoparticles prepared by acid hydrolysis of various starches," Starch - Stärke 64(5), 367-373. DOI: 10.1002/star.201100105

Kim, H.-Y., Park, D. J., Kim, J.-Y., and Lim, S.-T. (2013). "Preparation of crystalline starch nanoparticles using cold acid hydrolysis and ultrasonication," Carbohydrate Polymers 98(1), 295-301. DOI: 10.1016/j.carbpol.2013.05.085

Kizil, R., Irudayaraj, J., and Seetharaman, K. (2002). "Characterization of irradiated starches by using FT-Raman and FTIR spectroscopy," Journal of Agricultural and Food Chemistry 50(14), 3912-3918. DOI: 10.1021/jf011652p

Kumari, S., Yadav, B. S., and Yadav, R. B. (2020). "Synthesis and modification approaches for starch nanoparticles for their emerging food industrial applications: A review," Food Research International 128, 1-20. DOI:

10.1016/j.foodres.2019.108765

Lammers, K., Arbuckle-Keil, G., and Dighton, J. (2009). "FT-IR study of the changes in carbohydrate chemistry of three New Jersey pine barrens leaf litters during simulated control burning," Soil Biology and Biochemistry 41(2), 340-347. DOI:

10.1016/j.soilbio.2008.11.005

LeCorre, D., Bras, J., and Dufresne, A. (2010). "Starch nanoparticles: A review," Biomacromolecules 11(5), 1139-1153. DOI: 10.1021/bm901428y

LeCorre, D., Bras, J., and Dufresne, A. (2011). "Influence of botanic origin and amylose content on the morphology of starch nanocrystals," Journal of Nanoparticle Research 13, 7193-7208. DOI: 10.1007/s11051-011-0634-2

Lu, H., Xiong, L., Li, M., Chen, H., Xiao, J., Wang, S., Qiu, L., Bian, X., Sun, C., and Sun, Q. (2019). "Separation and characterization of linear glucans debranched from normal corn, potato and sweet potato starches," Food Hydrocolloids 89, 196-206. DOI: 10.1016/j.foodhyd.2018.10.043

Madzlan, K., Hasnisa, H., Sabeetha, S., and Dayana, M. N. (2012). "Extraction of starch and enzymatic production of high amylose starch from sweetpotato (Ipomea batatas) var. Telong," Journal of Tropical Agriculture and Food Science 40(2), 203-210.

Miao, M., Jiang, B., and Zhang, T. (2009). "Effect of pullulanase debranching and recrystallization on structure and digestibility of waxy maize starch," Carbohydrate Polymers 76(2), 214-221. DOI: 10.1016/j.carbpol.2008.10.007

Morrison, W. R., and Laignelet, B. (1983). "An improved colorimetric procedure for determining apparent and total amylose in cereal and other starches," Journal of Cereal Science 1(1), 9-20. DOI: 10.1016/S0733-5210(83)80004-6

Nara, S., and Komiya, T. (1983). "Studies on the relationship between water-satured state and crystallinity by the diffraction method for moistened potato starch," Starch Stärke 35(12), 407-410. DOI: 10.1002/star.19830351202

Nlandu, H., Belkacemi, K., Chorfa, N., Elkoun, S., Robert, M., and Hamoudi, S. (2019). "Flax nanofibrils production via supercritical carbon dioxide pre-treatment and enzymatic hydrolysis," The Canadian Journal of Chemical Engineering 98(1), 84-95. DOI: $10.1002 /$ cjce. 23596

Odeku, O. A. (2013). "Potentials of tropical starches as pharmaceutical excipients: A review," Starch - Stärke 65(1-2), 89-106. DOI: 10.1002/star.201200076 
Reddy, C. K., Luan, F., and Xu, B. (2017). "Morphology, crystallinity, pasting, thermal and quality characteristics of starches from adzuki bean (Vigna angularis L.) and edible kudzu (Pueraria thomsonii Benth)," International Journal of Biological Macromolecules 105(Part 1), 354-362. DOI: 10.1016/j.ijbiomac.2017.07.052

Rodrigues, A., and Emeje, M. (2012). "Recent applications of starch derivatives in nanodrug delivery," Carbohydrate Polymers 87(2), 987-994. DOI: 10.1016/j.carbpol.2011.09.044

Rodríguez-Pineda, L. M., Muñoz-Prieto, E. d. J., Rius-Alonso, C. A., and PalaciosAlquisira, J. (2018). "Preparation and characterization of potato starch microparticles with acrylamide by microwave radiation," Ciencia en Desarrollo 9(2), 149-159. DOI: 10.19053/01217488.v9.n2.2018.7783

Shi, M., and Gao, Q. (2011). "Physicochemical properties, structure and in vitro digestion of resistant starch from waxy rice starch," Carbohydrate Polymers 84(3), 1151-1157. DOI: 10.1016/j.carbpol.2011.01.004

Silveira, M. H. L., Morais, A. R. C., Lopes, A. M. d., Olekszyszen, D. N., Bogel-Łukasik, R., Andreaus, J., and Ramos, L. P. (2015). "Current pretreatment technologies for the development of cellulosic ethanol and biorefineries," ChemSusChem 8(20), 33663390. DOI: $10.1002 /$ cssc. 201500282

Singh, J., McCarthy, O. J., Singh, H., and Moughan, P. J. (2008). "Low temperature postharvest storage of New Zealand Taewa (Maori potato): Effects on starch physicochemical and functional characteristics," Food Chemistry 106(2), 583-596. DOI: 10.1016/j.foodchem.2007.06.041

Tan, Y., Xu, K., Li, L., Liu, C., Song, C., and Wang, P. (2009). "Fabrication of sizecontrolled starch-based nanospheres by nanoprecipitation," ACS Applied Materials \& Interfaces 1(4), 956-959. DOI: 10.1021/am900054f

Warren, F. J., Gidley, M. J., and Flanagan, B. M. (2016). "Infrared spectroscopy as a tool to characterise starch ordered structure - A joint FTIR-ATR, NMR, XRD and DSC study," Carbohydrate Polymers 139, 35-42. DOI: 10.1016/j.carbpol.2015.11.066

Wong, C. W., Muhammad, S. K. S., Dzulkifly, M. H., Saari, N., and Ghazali, H. M. (2007). "Enzymatic production of linear long-chain dextrin from sago (Metroxylon sagu) starch," Food Chemistry 100(2), 774-780. DOI: 10.1016/j.foodchem.2005.10.040

Wu, J., Huang, Y., Yao, R., Deng, S., Li, F., and Bian, X. (2019). "Preparation and characterization of starch nanoparticles from potato starch by combined solid-state acid-catalyzed hydrolysis and nanoprecipitation," Starch - Stärke 71(9-10), 1900095. DOI: $10.1002 /$ star.201900095

Xiao, C. (2013). "Current advances of chemical and physical starch-based hydrogels," Starch - Stärke 65(1-2), 82-88. DOI: 10.1002/star.201200113

Zhang, L., Cai, W., Shan, J., Zhang, S., and Dong, F. (2014). "Physical properties and loading capacity of gelatinized granular starches," Industrial Crops and Products 53, 323-329. DOI: 10.1016/j.indcrop.2013.12.053

Article submitted: May 18, 2021; Peer review completed: September 11, 2021; Revised version received and accepted: September 24, 2021; Published: September 29, 2021. DOI: $10.15376 /$ biores.16.4.7671-7683 